\title{
The incidence of psychoses in diverse settings, INTREPID (2): a feasibility study in India, Nigeria, and Trinidad
}

\author{
C. Morgan ${ }^{1,2 *}$, S. John ${ }^{3}$, O. Esan ${ }^{4}$, M. Hibben ${ }^{5}$, V. Patel $^{6}$, H. Weiss ${ }^{6}$, R. M. Murray ${ }^{1,7}$, G. Hutchinson ${ }^{5}$, \\ O. Gureje ${ }^{4}$, R. Thara ${ }^{3}$ and A. Cohen ${ }^{6}$ \\ ${ }^{1}$ Health Service and Population Research Department, Society and Mental Health Research Group, Centre for Epidemiology and Public Health, \\ Institute of Psychiatry, King's College London, UK \\ ${ }^{2}$ National Institute for Health Research (NIHR) Mental Health Biomedical Research Centre at South London and Maudsley NHS Foundation Trust \\ and King's College London, UK \\ ${ }^{3}$ Schizophrenia Research Foundation, Chennai, India \\ ${ }^{4}$ Department of Psychiatry, University of Ibadan, Nigeria \\ ${ }^{5}$ Department of Psychiatry, University of the West Indies, Trinidad \\ ${ }^{6}$ Department of Population Health, London School of Hygiene and Tropical Medicine, London, UK \\ ${ }^{7}$ Psychosis Studies Department, Institute of Psychiatry, King's College London, UK
}

Background. There are striking global inequities in our knowledge of the incidence, aetiology, and outcome of psychotic disorders. For example, only around $10 \%$ of research on incidence of psychotic disorders originates in low- and middleincome countries. We established INTREPID I to develop, implement, and evaluate, in sites in India (Chengalpet), Nigeria (Ibadan), and Trinidad (Tunapuna-Piarco), methods for identifying and recruiting untreated cases of psychosis, as a basis for investigating incidence and, subsequently, risk factors, phenomenology, and outcome. In this paper, we compare case characteristics and incidence rates across the sites.

Method. In each site, to identify untreated cases of psychoses in defined catchment areas, we established case detection systems comprising mental health services, traditional and spiritual healers, and key informants.

Results. Rates of all untreated psychoses were 45.9 (per 100000 person-years) in Chengalpet, 31.2 in Ibadan, and 36.9 in Tunapuna-Piarco. Duration of psychosis prior to detection was substantially longer in Chengalpet (median 232 weeks) than in Ibadan (median 13 weeks) and Tunapuna-Piarco (median 38 weeks). When analyses were restricted to cases with a short duration (i.e. onset within preceding 2 years) only, rates were 15.5 in Chengalpet, 29.1 in Ibadan, and 26.5 in Tunapuna-Piarco. Further, there was evidence of age and sex differences across sites, with an older average age of onset in Chengalpet and higher rates among women in Ibadan.

Conclusion. Our findings suggest there may be differences in rates of psychoses and in the clinical and demographic profiles of cases across economically and socially distinct settings.

Received 2 July 2015; Revised 10 February 2016; Accepted 11 February 2016; First published online 28 March 2016

Key words: Epidemiology, incidence, India, Nigeria, psychoses, Trinidad.

\section{Introduction}

Our understanding of the rate at which psychotic disorders occur in populations has changed in the past 10 years. In contrast to what was previously assumed, there is now strong evidence that the incidence of schizophrenia and other psychoses varies across geographical areas and social groups (McGrath et al.

* Address for correspondence: Professor C. Morgan, Health Service and Population Research Department, Society and Mental Health Research Group, Centre for Epidemiology and Public Health, Institute of Psychiatry, King's College London, UK.

(Email: craig.morgan@kcl.ac.uk)
2004; Fearon \& Morgan, 2006; Kirkbride et al. 2006). This is important because understanding the origins of these variations may provide clues to aetiology, in particular to the kinds of environments that increase or decrease risk for disorder. Largely as a consequence of this, there has been an upsurge of research on (socio-) environmental factors (e.g. Morgan et al. 2008; Van Os et al. 2010), much of it suggesting that fragmented neighbourhoods (Allardyce et al. 2005; Zammit et al. 2010), disadvantaged social statuses (Bourque et al. 2011; Morgan et al. 2014a, b), and negative interpersonal experiences (Varese et al. 2012; Morgan et al. 2014c) are associated with risk of psychotic disorders - findings which mirror those from

This is an Open Access article, distributed under the terms of the Creative Commons Attribution licence (http://creative commons.org/licenses/by/4.0/), which permits unrestricted re-use, distribution, and reproduction in any medium, provided the original work is properly cited. 
much earlier work (e.g. Faris \& Dunham, 1939; Hollingshead \& Redlich, 1958). What is remarkable about this research is that it has been conducted in a relatively narrow range of settings, i.e. select centres in high-income countries. It is only a slight exaggeration to say that we know nothing about rates of psychotic disorders in the rest of the world. For example, even in the WHO Ten Country study (Jablensky et al. 1992) the data were sufficient to allow estimates of incidence in only one low- and middle-income country (India). While this remains the case, our understanding of how environments and experiences over the life-course impact on risk and shape the varied manifestations and outcomes of psychotic disorders will be partial.

\section{Incidence studies in other places}

To clarify the extent and nature of existing findings from incidence studies of psychotic disorder outside, geographically, of North America, Europe, and Australasia, we conducted a review of the relevant literature, first drawing from the review by McGrath et al. (2004) and then repeating this to cover the period since (i.e. 1 January 2002-31 December 2014).

We identified 14 studies (eight from McGrath et al. 2004, six from our search) spread across a wide range of geographical settings (Table 1). In only one country (Surinam) was there more than one study and a majority (7/12 that provided information) included fewer than 100 cases. Reported incidence rates varied. However, there were no discernible patterns by geographical area and there was considerable heterogeneity in the methods and quality of the studies included, making direct comparisons difficult and limiting what can be inferred about the reasons for variation. For example, there was little consistency in methods for case detection, in age groups covered, and in symptomatic and diagnostic inclusion criteria and assessment. All these aspects of study design influence the number of cases counted and thereby estimated incidence rates. Most importantly, in settings where mental health services are relatively underdeveloped or where access is limited, studies that rely solely on such services inevitably produce biased estimates of incidence. Only six of the 14 studies included in our review attempted to extend casefinding beyond mental health services; in none is any information given about how many cases, if any, were detected through non-mental health service sources.

\section{Aims}

INTREPID I is a feasibility study. Our aim was to develop, implement, and evaluate, in three sites in India, Nigeria, and Trinidad, methods and strategies for identifying and recruiting untreated cases of psychosis (i.e. untreated at start of periods of case detection), as a basis for investigating incidence and, subsequently, risk factors (within a case-control design), phenomenology, and course and outcome (Morgan et al. 2015). Here we report on the implementation of and results from case-finding, in particular focusing on: $(a)$ the sources through which cases were identified, $(b)$ clinical and demographic profiles of included cases, and (c) incidence rates of untreated psychoses of both long (i.e. $>2$ years) and short (i.e. <2 years) duration.

\section{Method}

INTREPID I is a population-based programme designed to implement and evaluate methods for identifying, assessing, and following untreated cases of psychosis and controls in three sites: Chengalpet (near Chennai), India; Ibadan South East and Ona Ara, Nigeria; and Tunapuna-Piarco, Trinidad (Morgan et al. 2015). This programme is, in part, designed to investigate psychoses in the regions and countries from which the majority of migrants to the UK originate, and this primarily determined the choice of countries. The specific sites were chosen to ensure they contained a mix of urban and rural areas.

\section{Sites and populations at risk}

The sites included in INTREPID I are economically, socially, and culturally diverse (Morgan et al. 2015; Supplementary Table S1). All are in countries that have experienced recent periods of rapid economic growth and urbanization. However, rates of poverty, literacy, and life expectancy differ. In Nigeria, for example, an estimated $68 \%$ live in poverty (i.e. on < $\$ 1.25$ per day), compared with around $32 \%$ in India and $4 \%$ in Trinidad. Life expectancy is also much lower in Nigeria (52 years) than in India (66 years) and Trinidad (70 years). This noted, data on these developmental markers are not available at site level and, given inevitable within-country variations, this means caution is needed in generalizing findings from our study to the country level. In each site, geographically demarcated catchment areas were defined (Supplementary Table S2). In Chengalpet and Tunapuna-Piarco, case-finding was conducted over a 7-month period and in Ibadan over a 6-month period. A 6-month period of case detection was set at the outset, on the basis that this would enable us to identify a sufficient number of cases to evaluate feasibility. Resources allowed us to extend case-finding for 1 month in Chengalpet and Tunapuna-Piarco. 
Table 1. Studies of incidence of psychosis in countries outside of North America, Europe, and Australasia ${ }^{\text {a }}$

\begin{tabular}{|c|c|c|c|c|c|c|c|c|c|c|}
\hline Site & Reference & $\begin{array}{l}\text { Study } \\
\text { date(s) }\end{array}$ & Age, years & $\begin{array}{l}\text { Diagnostic } \\
\text { group }(\mathrm{s})^{\mathrm{b}}\end{array}$ & Case-finding ${ }^{c}$ & $\begin{array}{l}\text { Population } \\
\text { at risk }^{\mathrm{d}}\end{array}$ & $\begin{array}{l}\text { Years } \\
\text { at risk }\end{array}$ & $\begin{array}{l}\text { No. of } \\
\text { cases }\end{array}$ & $\begin{array}{l}\text { Incidence } \\
\text { rates }^{\mathrm{e}}\end{array}$ & $\begin{array}{l}\text { Level of } \\
\text { development }\end{array}$ \\
\hline Beijing, China* & Yucun et al. (1987) & 1974-1979 & $\geqslant 15$ & $\begin{array}{l}\text { Schizophrenia } \\
\text { (unclear) }\end{array}$ & $\begin{array}{l}\text { Community } \\
\text { survey }\end{array}$ & 〜190000 & 5 & $\begin{array}{l}\text { Not } \\
\text { specified }\end{array}$ & 11.0 & $\begin{array}{l}\text { Upper } \\
\text { middle }\end{array}$ \\
\hline Singapore* & Tsoi \& Chen (1979) & 1975 & $10-80$ & $\begin{array}{l}\text { Schizophrenia } \\
\text { (clinical) }\end{array}$ & $\begin{array}{l}\text { First } \\
\text { admission }\end{array}$ & 1788945 & 1 & 660 & 29.3 & High \\
\hline $\begin{array}{l}\text { Chandigarh, } \\
\text { India* }\end{array}$ & $\begin{array}{l}\text { Jablensky et al. (1992); } \\
\text { Wig et al. (1993) }\end{array}$ & 1978-1980 & $15-54$ & $\begin{array}{l}\text { Schizophrenia } \\
\text { (research) }\end{array}$ & First contact + & $\begin{array}{l}205786 \text { urban } \\
61642 \text { rural }\end{array}$ & $\begin{array}{l}2 \\
2 \\
2 \\
2\end{array}$ & $\begin{array}{l}155 \\
54\end{array}$ & $\begin{array}{l}\text { 38.0 Broad } \\
\text { 9.0 Narrow } \\
\text { 44.0 Broad } \\
\text { 12.0 Narrow }\end{array}$ & $\begin{array}{l}\text { Lower } \\
\text { middle }\end{array}$ \\
\hline Greenland* & $\begin{array}{l}\text { Lynge \& Jacobsen } \\
\text { (1995) }\end{array}$ & 1980-1983 & $15-34^{\mathrm{g}}$ & $\begin{array}{l}\text { Schizophrenia } \\
\text { (clinical) }\end{array}$ & $\begin{array}{l}\text { First } \\
\text { admission }\end{array}$ & 39012 & 3 & 37 & 31.6 & High \\
\hline Madras, India* & Rajkumar et al. (1993) & 1987-1988 & $\geqslant 15$ & $\begin{array}{l}\text { Schizophrenia } \\
\text { (research }\end{array}$ & $\begin{array}{l}\text { Community } \\
\text { survey }\end{array}$ & 25661 & 1 & 15 & $58.5^{\mathrm{h}}$ & $\begin{array}{l}\text { Lower } \\
\text { middle }\end{array}$ \\
\hline Jamaica* & $\begin{array}{l}\text { Hickling \& } \\
\text { Rodgers-Johnson } \\
\text { (1995) }\end{array}$ & 1992 & $15-54$ & $\begin{array}{l}\text { Schizophrenia } \\
\text { (research) }\end{array}$ & First-contact & 1350000 & 1 & 317 & $\begin{array}{l}\text { 23.6 Broad } \\
\text { 20.9 Narrow }\end{array}$ & $\begin{array}{l}\text { Upper } \\
\text { middle }\end{array}$ \\
\hline Surinam & Hanoeman et al. (2002) & 1992-1993 & $15-54$ & $\begin{array}{l}\text { Schizophrenia } \\
\text { (clinical) }\end{array}$ & $\begin{array}{l}\text { First } \\
\text { admission }\end{array}$ & 226692 & 2 & 73 & $16.8^{\mathrm{i}}$ & $\begin{array}{l}\text { Upper } \\
\text { middle }\end{array}$ \\
\hline Trinidad ${ }^{*}$ & Bhugra et al. (1996) & $\begin{array}{l}\text { Not } \\
\text { specified }\end{array}$ & $15-54$ & $\begin{array}{l}\text { All psychoses } \\
\text { (research) }\end{array}$ & First contact + & 214048 & 1 & 56 & $\begin{array}{l}\text { 26.2 All } \\
\text { 21.5 Broad } \\
\text { 15.9 Narrow }\end{array}$ & High \\
\hline Barbados* & Mahy et al. (1999) & 1995 & $18-54$ & $\begin{array}{l}\text { All psychoses } \\
\text { (research) }\end{array}$ & First contact + & 142000 & 1 & 50 & $\begin{array}{l}\text { 35.2 All } \\
\text { 31.7 Broad } \\
\text { 28.2 Narrow }\end{array}$ & High \\
\hline Taiwan & Chien et al. (2004) & 1997-2001 & $\geqslant 15$ & $\begin{array}{l}\text { Schizophrenia } \\
\text { (clinical) }\end{array}$ & $\begin{array}{l}\text { Insurance } \\
\text { register }\end{array}$ & 132824 & 5 & 419 & 63.1 & High \\
\hline Surinam & Selten et al. (2005) & $2002-2003$ & $15-54$ & $\begin{array}{l}\text { Schizophrenia } \\
\text { (research) }\end{array}$ & First-contact + & Not given & 1 & 64 & $17.7^{\mathrm{i}}$ & $\begin{array}{l}\text { Upper } \\
\text { middle }\end{array}$ \\
\hline Sao Paulo, Brazil & Menezes et al. (2007) & 2002-2004 & $18-64$ & $\begin{array}{l}\text { All psychoses } \\
\text { (research) }\end{array}$ & First contact & 926081 & 2.5 & 367 & 15.8 & $\begin{array}{l}\text { Upper } \\
\text { middle }\end{array}$ \\
\hline Israel & Kodesh et al. (2012) & 2003-2009 & $\begin{array}{l}\text { Not } \\
\text { specified }\end{array}$ & $\begin{array}{l}\text { Schizophrenia } \\
\text { (clinical) }\end{array}$ & Case register & Not given & 6 & Not given & 50.0 & High \\
\hline
\end{tabular}




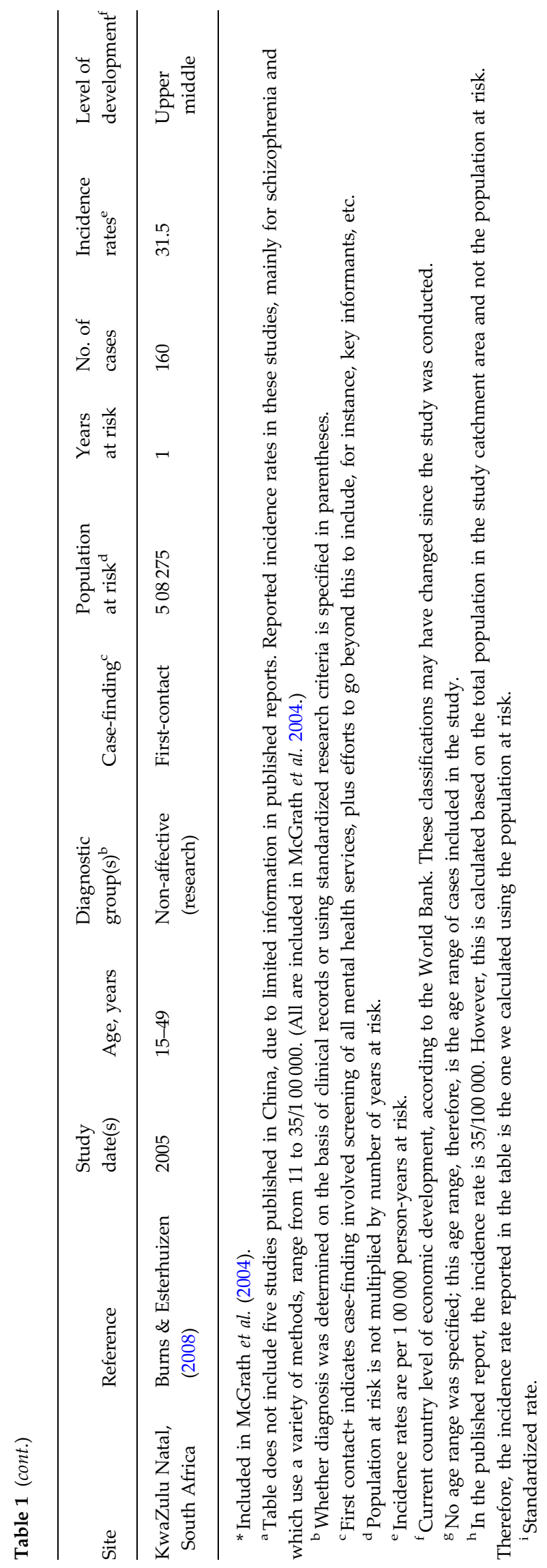

\section{Detection systems}

We established extensive case detection systems in each site, tailored to the local healthcare systems, that incorporated all mental health providers (public and private, including psychiatrists and mental health nurses), the major spiritual and traditional healers, and a network of key informants (including primary-care doctors and nurses) (Morgan et al. 2015). We further provided all staff, healers, and informants with training and information materials on psychoses (developed from qualitative studies in each site; Cohen et al. unpublished data) to ensure a shared understanding of the problems and behaviours of interest. In Chengalpet, this system was augmented by locating five research workers within the local communities to periodically approach local residents at communal meeting points (where groups of residents would often congregate) to enquire about possible cases.

\section{Inclusion and exclusion criteria}

Our inclusion and exclusion criteria were identical to those used in the UK AESOP study (Kirkbride et al. 2006), which in turn were based on those used in the WHO Ten Country study (Jablensky et al. 1992), i.e. inclusion criteria: age 18-64 years; resident in catchment area at time of case detection; evidence of psychotic symptoms or experiences in past 12 months; not treated with antipsychotics for 3 continuous months prior to the start of recruitment. Exclusion criteria: evidence of psychotic symptoms precipitated by an organic cause; central nervous system disease; transient psychotic symptoms resulting from acute intoxication.

These criteria were purposefully broad (i.e. all psychoses without substantive treatment with antipsychotic medication prior to the start of the study), and, following most previous studies, did not specify a limit on the length of psychosis prior to detection. However, for analyses, we did distinguish cases with long (i.e. $>2$ years) and short (i.e. $<2$ years) duration of psychosis. In studies in the UK (e.g. AESOP), over $80 \%$ of cases included in incidence samples have a duration of untreated psychosis of $<2$ years (Morgan et al. 2006). Our short duration group, then, was defined to be as comparable as possible to previous studies in settings with more developed and accessible mental health services.

\section{Case ascertainment and data collection}

In the study periods in each site, we identified all those aged 18-64 years who presented to mental health services or spiritual and traditional healers or who were known to key informants (including primary-care doctors and nurses) and who met our inclusion criteria. Using the terminology from Table 1 , this case-finding 
strategy is first-contact + , i.e. screening of all mental health services for first contact cases, plus efforts to go beyond this to include healers and informants. A team of researchers in each site was responsible for checking, on at least a weekly basis, with all providers, healers, and informants. All potential cases were screened for inclusion using the Screening Schedule for Psychosis (Jablensky et al. 1992). Information on sociodemographics and past and current symptoms and health service contacts and treatment on all those who passed the screen was collated from potential cases, informants, and clinical records (where available) using translated versions of the MRC Sociodemographic Schedule (Mallett, 1997), the WHO Personal and Psychiatric History Schedule (PPHS; WHO, 1993), and the Schedules for Clinical Assessment in Neuropsychiatry (SCAN; WHO, 1992). This information was used to determine inclusion and diagnosis.

All researchers in each site underwent extensive training throughout the project in inclusion and exclusion criteria and in each assessment that comprised: face to face training; online training materials (http:// www.intrepidresearch.org/training); and ongoing supervision from site PIs (R.T., O.G., G.H.). For all relevant instruments we conducted inter-rater reliability exercises. Researchers in each site independently rated videos of assessments (http://www.intrepidresearch.org/training) and ratings by each pair of researchers were compared by calculating kappa statistics. These indicated moderate (range $0.41-0.60$ ) to good (range 0.61-0.80) agreement among raters across all sites. Diagnoses were determined by consensus (Kirkbride et al. 2006). In each site, researchers presented information from clinical interviews and, where available, clinical notes to the research team and PIs. On the basis of this, and ensuing discussions, consensus diagnoses were agreed.

\section{Leakage}

In each site, at the end of case recruitment we conducted leakage studies to identify any possible cases meeting our inclusion criteria who may have been missed. This involved researchers systematically checking, where possible, new admissions ledgers and registers for in-patient and out-patient services and, as appropriate, completing final checks with healers and informants.

\section{Analysis}

Incidence rates are expressed per 100000 person-years at risk. Direct standardization was used to estimate sex and age-standardize rates across sites using the World (WHO 2000-2015) Standard Population (http://seer. cancer.gov/stdpopulations/world.who.html). To examine variations in incidence, incidence rate ratios were modelled using Poisson regression to adjust for sex and age.

\section{Ethical standards}

The authors assert that all procedures contributing to this work comply with the ethical standards of the relevant national and institutional committees on human experimentation and with the Helsinki Declaration of 1975, as revised in 2008.

\section{Results}

In each catchment area we screened large numbers of potential cases during the periods of case identification (Chengalpet 480, Ibadan 559, Trinidad 117). The majority were not eligible, primarily because of prior treatment or residence outside of the catchment areas, and we had insufficient information to determine eligibility on a small number (Chengalpet 18, Ibadan 0 , Tunapuna-Piarco 9). From those screened, we identified 147 cases who met our inclusion criteria (Chengalpet 64, Ibadan 48, Tunapuna-Piarco 35) (see flow charts in the supplementary material). There were marked differences between sites in the sources through which cases were identified, reflecting differences in the structure of local healthcare systems (Morgan et al. 2015). In Tunapuna-Piarco, over 90\% were identified through mental health services; in Ibadan around half were identified through services and around half through spiritual and traditional healers; and in Chengalpet, around 90\% were identified through non-providers (i.e. key informants and local residents) (Supplementary Table S2).

\section{Clinical and demographic characteristics}

In Chengalpet and Tunapuna-Piarco, roughly half the cases received a diagnosis of schizophrenia (ICD-10, F20.X) and half of another psychotic disorder (e.g. delusional disorder, bipolar disorder with psychotic symptoms, etc.). By contrast, almost $90 \%$ of cases in Ibadan received a diagnosis of schizophrenia. In Chengalpet, duration of psychosis prior to detection (median, 232 weeks) was longer than in both Ibadan (median 13 weeks) and Tunapua-Piarco (median 38 weeks). Following onset, almost half the cases in Tunapuna-Piarco first sought or received help from a mental health professional and, by the point of inclusion in the study, over $90 \%$ had had a contact with a mental health professional. This contrasts with Chengalpet and Ibadan, where a majority first sought or received help from a spiritual or traditional healer and, at point of inclusion, around a third in each site 
had had no contact with a mental health professional (Supplementary Table S3).

The cohort in Chengalpet was older (mean age 39.8 years) at detection than in both Ibadan (mean age 31.0 years) and Tunapuna-Piarco (mean age 33.4 years). This, however, was mainly a reflection of differences in duration of psychosis prior to detection; when age of onset was considered, the evidence for differences in age of onset was weaker (mean age of onset: Chengalpet 33.8, Ibadan, 30.3, Tunapuna-Piarco, 31.6; $p=0.150)$. The gender distributions also differed. There were more women in Ibadan $(68.8 \%)$ and in Chengalpet $(56.2 \%)$ and fewer women in TunapunaPiarco (42.9\%). In Chengalpet (but not Ibadan or Tunapuna-Piarco), these proportions were reversed for cases with schizophrenia (i.e. fewer women, $43.2 \%$ ) (Supplementary Table S3).

\section{Incidence rates of untreated psychoses}

The overall age and sex-standardized rates of all untreated psychoses were 45.9 in Chengalpet, 31.2 in Ibadan, and 36.9 in Tunapuna-Piarco, with no strong evidence that these rates varied by more than chance, i.e. Ibadan $v$. Chengalpet [incidence rate ratio (IRR) 0.82, 95\% confidence interval (CI) 0.56-1.19], Tunapuna-Piarco v. Chengalpet (IRR 0.83, 95\% CI 0.55-1.25) (Table 2, Fig. 1a). This was also the case for schizophrenia, i.e. no strong evidence of variation. There was, however, some evidence that the rate of other psychoses was lower in Ibadan compared with the other sites, e.g. Ibadan $v$. Chengalpet (IRR 0.20, 95\% CI 0.08-0.51).

When we restricted the analyses to only those with a short duration of psychosis, there was more evidence of variations. For example, the overall age- and sexstandardized rates, compared with Chengalpet [incidence rate (IR) 15.5], were higher in Ibadan (IR 29.1, IRR 2.06, 95\% CI 1.25-3.41) and Trinidad (IR 26.5, IRR 1.73, 95\% CI 0.98-3.05) (Table 2, Fig. 1b). These differences were mainly in rates of schizophrenia, i.e. Ibadan $v$. Chengalpet (IRR 3.66, 95\% CI 1.92-6.97) and Tunapuna-Piarco $v$. Chengalpet (IRR 1.84, 95\% CI 0.85-3.98). Nonetheless, the lower rate of other psychoses in Ibadan was still, to some extent, evident when restricted to short duration cases, e.g. Ibadan $v$. Chengalpet (IRR 0.37, 95\% CI 0.12-1.16).

\section{Sex- and age-specific incidence rates}

Given that the number of cases in each site was relatively small, it is difficult to make confident inferences regarding patterns of incidence by sex or age. Still, for completeness, analyses by sex and age are provided in Supplementary Tables S4-S6 and Supplementary Figs S1 and S2.
Tentatively, in Chengalpet and Tunapuna-Piarco there was no evidence of sex differences in rates of all psychoses [women $v$. men: Chengalpet (IRR 1.33, 95\% CI 0.81-2.17); Tunapuna-Piarco (IRR 0.75, 95\% CI 0.39-1.47)]. However, when stratified by diagnosis, there was some evidence that the rate of other psychoses was higher in women in Chengalpet (IRR 2.94, 95\% CI 1.24-6.95). In Ibadan there was some evidence that overall rates were higher in women (IRR 1.97, 95\% CI 1.07-3.63); this broadly held for schizophrenia (IRR 1.67, 95\% CI 0.89-3.12). When analyses were restricted to those with a short duration of psychosis, these patterns were broadly the same (Supplementary Table S3). Finally, and more tentatively still, our data suggest age-specific rates in Ibadan and TunapunaPiarco broadly follow what has been previously reported, i.e. peak during 20s with a decline thereafter, but not in Chengalpet, where rates were more consistent through to mid-40s (Supplementary Tables S4 and S5; Supplementary Figs S1 and S2).

\section{Leakage studies}

From the leakage studies we identified a further 21 possible cases (Chengalpet 9, Ibadan 4, Tunapuna-Piarco 8), suggesting upwards of between $8 \%$ and $18 \%$ of cases were missed in each site. Due to limited information available on these individuals, we did not include them in the analyses above. However, they do provide a basis for estimating the upper range for incidence rates in each site (Supplementary Table S7).

\section{Discussion}

We identified more cases in each catchment area than anticipated and our estimated incidence rates are at the upper end of those reported in previous studies (McGrath et al. 2004). This allowed us to examine in more detail than anticipated variations within and among sites in the clinical and demographic characteristics of cases and rates of disorder. We found that: $(a)$ in Chengalpet and Ibadan, most cases were identified outside of mental health services and, at point of ascertainment, around a third in each of these sites had not had any contact with a health professional; $(b)$ age of onset was older and duration of psychosis was longer in Chengalpet; and (c) the incidence of short duration psychosis was higher in Ibadan and Tunapuna-Piarco than Chengalpet, with this being most marked for schizophrenia in Ibadan.

\section{Methodological issues}

Before considering these findings further, a number of methodological issues need to be addressed. First, while the number of cases included in each site is 
Table 2. Age and sex standardized rates of all and of short duration psychosis

\begin{tabular}{|c|c|c|c|c|c|c|c|c|c|c|c|}
\hline & $\begin{array}{l}\text { Person-years } \\
\text { at risk }\end{array}$ & $\begin{array}{l}\text { All } \\
\text { cases }\end{array}$ & Rate $^{\mathrm{a}}$ & $95 \%$ CI & IRR & $95 \%$ CI & $\begin{array}{l}\text { Short } \\
\text { duration } \\
\text { cases }\end{array}$ & Rate $^{c}$ & $95 \%$ CI & $\mathrm{IRR}^{\mathrm{b}}$ & $95 \%$ CI \\
\hline \multicolumn{12}{|l|}{ All psychoses } \\
\hline Chengalpet & 148961 & 64 & 45.9 & $34.5-57.3$ & 1.00 & - & 23 & 15.5 & $9.1-22.0$ & 1.00 & - \\
\hline Ibadan & 135240 & 48 & 31.2 & $22.2-40.3$ & 0.82 & $0.56-1.19$ & 45 & 29.1 & $20.4-37.8$ & 2.06 & $1.25-3.41$ \\
\hline Tunapuna & 98260 & 35 & 36.9 & $24.6-49.1$ & 0.83 & $0.55-1.25$ & 25 & 26.5 & $16.1-36.9$ & 1.73 & $0.98-3.05$ \\
\hline \multicolumn{12}{|l|}{ Schizophrenia } \\
\hline Chengalpet & 148961 & 37 & 27.2 & $18.3-36.0$ & 1.00 & - & 12 & 8.3 & $3.6-13.1$ & 1.00 & - \\
\hline Ibadan & 135240 & 43 & 27.5 & $19.1-36.0$ & 1.29 & $0.83-2.00$ & 41 & 26.3 & $18.1-34.5$ & 3.66 & $1.92-6.97$ \\
\hline Tunapuna & 98260 & 18 & 19.4 & $10.4-28.4$ & 0.73 & $0.42-1.29$ & 14 & 15.2 & $7.2-23.2$ & 1.84 & $0.85-3.98$ \\
\hline \multicolumn{12}{|l|}{$\begin{array}{l}\text { Other } \\
\text { psychoses }\end{array}$} \\
\hline Chengalpet & 148961 & 27 & 18.8 & $11.6-25.9$ & 1.00 & - & 11 & 7.2 & $2.9-11.5$ & 1.00 & - \\
\hline Ibadan & 135240 & 5 & 3.7 & $0.3-7.0$ & 0.20 & $0.08-0.51$ & 4 & 2.8 & $1.0-5.7$ & 0.37 & $0.12-1.16$ \\
\hline Tunapuna & 98260 & 17 & 17.4 & $9.1-25.7$ & 0.96 & $0.52-1.77$ & 11 & 11.3 & $4.6-18.0$ & 1.62 & $0.70-3.75$ \\
\hline
\end{tabular}

${ }^{\text {a }}$ All cases.

${ }^{\mathrm{b}}$ Adjusted for age and sex; modelled using Poisson regression.

${ }^{\mathrm{c}}$ Recent onset (i.e. duration of psychosis of $<2$ years) cases only.

similar to - and in many instances higher than - the numbers that have formed the basis for other reports, they are nonetheless relatively small. The study was primarily designed to evaluate feasibility and was not powered to test hypotheses concerning, for example, differences in rates of disorder among sites. Consequently, our data on the clinical and demographic characteristics of cases and our estimates of incidence rates and rate ratios are imprecise and necessarily tentative.

Second, we cannot exclude the possibility that - despite our efforts to extend case-finding beyond professional mental health services - we still missed cases. Our case detection systems in each site were not complete. For example, in Chengalpet we could only cover the major healing sites known to provide care for those with a mental disorder and, even then, consistently engaging with them was difficult, in part due to lack of trust (Morgan et al. 2015). To address this in Chengalpet, we incorporated an additional strategy of approaching local residents at communal meeting points to supplement case-finding. This identified a large number of cases with a long untreated disorder [i.e. $15(50 \%)$ of cases identified via this strategy had a duration of $>2$ years] and it may be that these cases were missed in other sites, a possibility hinted at by differences in duration of disorder among sites (especially the short duration in Ibadan). Consequently, some of the differences observed between Chengalpet and the other sites may be a function of this methodological difference. (Because of this, we now plan to incorporate a similar strategy into case-finding in the other sites in the next stage of our programme.) Related to this, the relatively low proportion of cases in Ibadan with a non-schizophrenia diagnosis may be due to our having missed cases with, for example, affective psychoses. Further, our leakage studies found additional possible cases in each site. The proportion of possible leakage cases identified, however, was in line with the proportions in other studies (e.g. AESOP, 13\%; Kirkbride et al. 2006). Still, that cases were very likely missed underscores the importance of conducting longer term programmes in which case detection systems develop and consolidate, as trust and familiarity increases.

Finally, our inclusion criteria were purposefully broad and in particular did not limit inclusion on the basis of duration of psychosis. This is in line with most previous studies, including AESOP (Kirkbride et al. 2006) and the WHO Ten-Country study (Jablensky et al. 1992), and this approach has the advantage of, ultimately, enabling samples to be subdivided by duration to examine whether and how this influences findings, which is indeed what we did. However, it is still important to keep this issue at the forefront when comparing findings across samples and studies. For example, in this study Chengalpet had the highest rates when all cases were included and the lowest rates when only those with a short duration were included. Indeed, this issue raises fundamental questions about how to estimate incidence rates in different settings. In the UK, for example, where mental health services are well developed and widely available and where over $80 \%$ of those included 

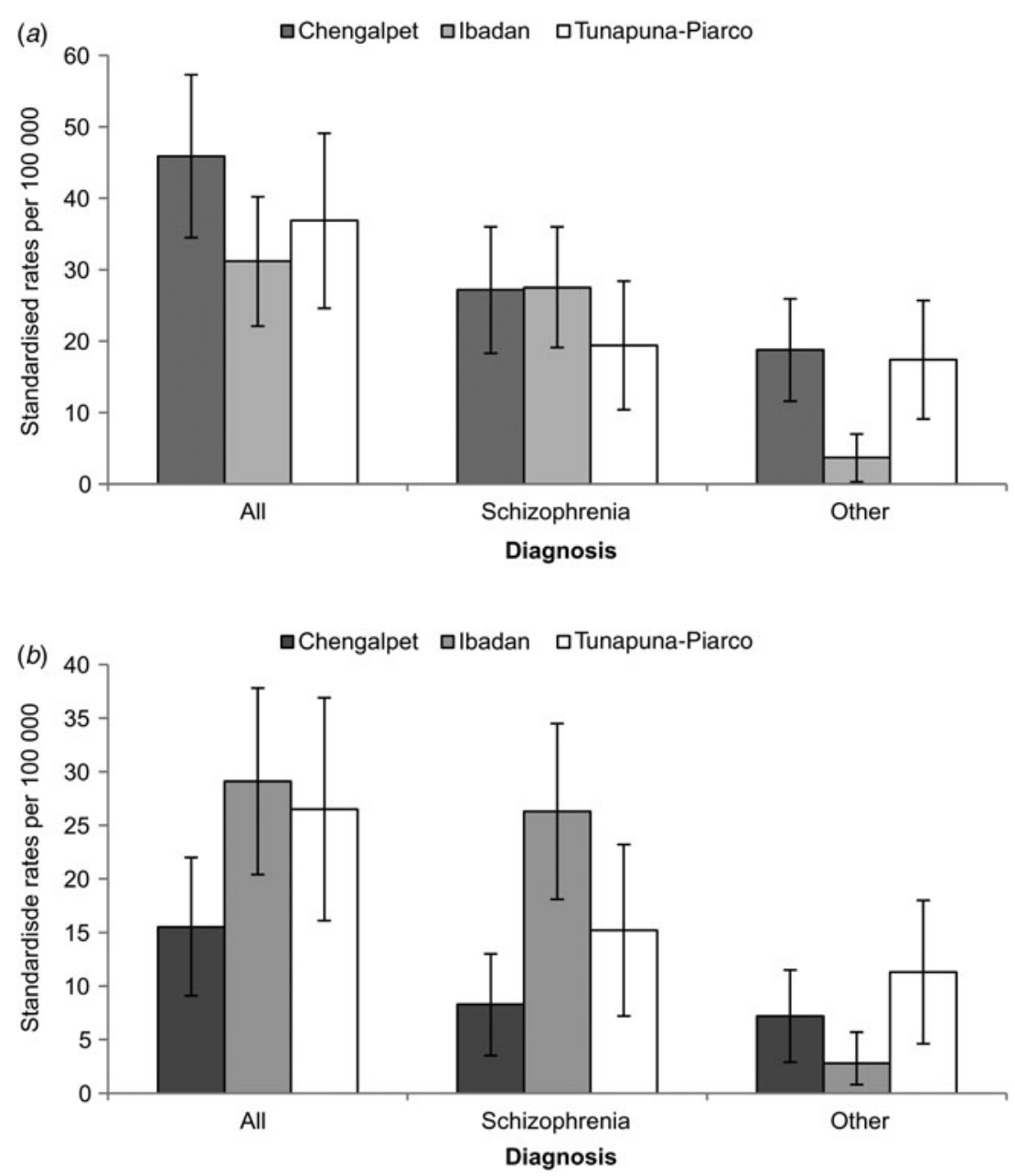

Fig. 1. Sex and age standardized rates by site and diagnosis. (a) All cases, (b) Short duration cases.

in incidence studies have a duration of psychosis of $<2$ years, first contact may provide a robust proxy for incidence. However, in Chengalpet it is less clear that such an approach is valid, as a relatively large proportion of included cases have a long-standing disorder. To deal with this, conducting studies over a longer period of time and basing estimates of incidence on short duration cases only may provide the basis for ensuring greater comparability of findings across diverse healthcare systems.

\section{Psychoses elsewhere}

The above methodological issues notwithstanding, the sheer paucity of research on untreated (incident) psychoses in settings other than North America, Europe, and Australasia means that our data have value both in adding to the available literature and in demonstrating the necessity and feasibility of conducting robust and comparable epidemiological studies of psychoses in diverse settings.
In all sites, our estimated incidence rates for all psychoses were high (31-46/100000), with the rate in Chengalpet being very similar to that reported for rural Chandigarh in the WHO Ten Country Study. They are at the upper end of rates reported in previous studies in low- and middle-income settings (see Table 1), including those that have used the most comparable methods. For example, studies in Brazil (Menezes et al. 2007), Trinidad (Bhugra et al. 1996), and Barbados (Mahy et al. 1999) that applied the same inclusion criteria reported rates between 15 and $35 / 100000$ per year. It is notable that the highest reported rate is from the study in Barbados, which as far as we could ascertain - was the only one that sought to extend case-finding to religious institutions. The authors, however, do not report on how many cases were found via the institutions they covered. Further, our rates are high compared with studies in high-income countries. In AESOP, for example, rates of all psychotic disorders in all sites was 32.1/100 000; this, however, was inflated by the inclusion of a 
site in London (49.4). In Bristol and Nottingham, rates were 20.4 and 23.9/100000 (Kirkbride et al. 2006). When only short duration cases were considered, rates were inevitably lower, further underscoring the importance of clarity and consistency on duration of disorder in comparing rates across studies. This noted, it does seem that case-finding methods that extend beyond mental health services in relatively lowresource settings do detect more cases and provide more valid estimates of incidence. Furthermore, it is important to bear in mind that incidence rates are unlikely to remain static over time. That our rates are relatively high may reflect increases under pressures of economic and population growth. This is, of course, speculation. It is, though, an intriguing hypothesis that can only be tested by constituting long-term programmes of research that can provide robust estimates in diverse settings over time.

While there was no strong evidence that rates for all cases varied across sites, there were intriguing differences in rates of short duration psychoses within and among sites. These have to be considered cautiously, as the above caveats about methodological limitations mean it is possible these differences are due to chance or bias. This notwithstanding, it is notable that - when considering short duration cases - rates differed across sites and the highest was in Ibadan, which contained the most densely populated area in any of the sites (population densities: Ibadan South East 15674/ $\mathrm{km}^{2}$,

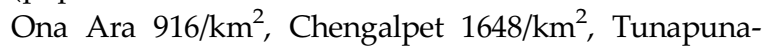
Piarco $476 / \mathrm{km}^{2}$ ). It is unclear to what extent the apparent association between the incidence of psychoses and population density extends beyond the northern European cities in which it has been reported. Menezes et al. (2007), for example, found a low rate of around 15/1 00000 in a catchment area in Sao Paulo, one of the most densely populated cities in the world. The association, then, between psychoses and population density may be more complex than research to date suggests; investigating this further in a wider range of cities, across different continents, may provide novel insights into the kinds of environments that foster the development of psychoses. One factor that may complicate the picture is infant mortality and life expectancy. If those most at risk of schizophrenia (e.g. due to prenatal and/or perinatal complications) are more likely to die in infancy or during childhood and adolescence, then rates of disorder may be low - or at least lower than they would otherwise be - in countries with higher infant mortality rates and lower life expectancy. Furthermore, the low rates in Chengalpet and relatively high rates in Ibadan and Tunapuna-Piarco mirror differences observed in Europe in migrants from India, West Africa, and the Caribbean (e.g. Fearon et al. 2006), a tantalizing observation that further hints at the potential for studies in such settings to cast light on population differences observed in high-income countries.

There were also noteworthy differences among sites in the age and sex distributions of the samples. Even after accounting for duration of illness, the average age of onset was older in Chengalpet than in Ibadan and Tunapuna-Piarco; and in both Ibadan and Tunapuna-Piarco, while the age distribution of risk broadly followed the pattern reported elsewhere (i.e. peak during 20s and dropping off thereafter), the average age of onset was still at the high end of what has been reported in other studies, both in high-income countries (McGrath et al. 2004) and in previous studies in low- and middle-income countries (e.g. around 50\% of those included in the India and Nigeria sites of the WHO Ten-Country study were aged 15-24 years). It is of note, in relation to this, that studies in high-income countries have tended to find an older average age of onset the broader the case-finding net has been cast (e.g. AESOP; Kirkbride et al. 2006). While our sample sizes are such that we must be cautious in overinterpreting the findings on age, they do nonetheless at least raise the possibility that age of onset may differ across settings, which may (in turn) reflect differences in the distribution of and exposure to environmental risk factors over the life-course. A similar observation can be made regarding sex. That is, the higher incidence in women in Ibadan may be due to chance or an artefact of the study; alternatively, it may reflect a real difference in the sex distribution (and in risk factors) across settings. At the very least, these findings raise questions about how universal the age and sex distributions typically reported in studies from high-income countries are.

\section{Conclusion}

Our study demonstrates the feasibility - and necessity of conducting comparable epidemiological studies of psychoses in more diverse settings, which are tailored to local healthcare systems. Such work has the potential to broaden the scope, and substantially increase the rigour and value, of research on psychoses beyond the usual settings, producing data of importance for our understanding of all aspects of psychoses and of direct relevance to the needs of local populations.

\section{Supplementary material}

For supplementary material accompanying this paper visit http://dx.doi.org/10.1017/S0033291716000441

\section{Acknowledgements}

This research is funded by the Wellcome Trust (WT094525). Craig Morgan is further supported by 
funding from the Wellcome Trust (WT087417); European Union (European Community's Seventh Framework Program (grant agreement no. HEALTHF2-2009-241909) (Project EU-GEI)); and a European Research Council Consolidator Award (ERC-2014CoG - 648837_REACH).

\section{Declaration of Interest}

Robin Murray is an editor of Psychological Medicine.

\section{References}

Allardyce J, Gilmour H, Atkinson J, Rapson T, Bishop J, McCreadie RG (2005). Social fragmentation, deprivation and urbanicity: relation to first-admission rates for psychoses. British Journal of Psychiatry 187, 401-406.

Bhugra D, Hilwig M, Hossein B, Marceau H, Neehall J, Leff J, Mallett R, Der G (1996). First-contact incidence rates of schizophrenia in Trinidad and one-year follow-up. British Journal of Psychiatry 169, 587-592.

Bourque F, van der Ven E, Malla A (2011). A meta-analysis of the risk for psychotic disorders among first- and secondgeneration immigrants. Psychological Medicine 41, 897-910.

Burns JK, Esterhuizen T (2008). Poverty, inequality and the treated incidence of first-episode psychosis: an ecological study from South Africa. Social Psychiatry and Psychiatric Epidemiology 43, 331-335.

Chien IC, Chou YJ, Lin CH, Bih SH, Chou P, Chang HJ (2004). Prevalence and incidence of schizophrenia among national health insurance enrollees in Taiwan, 1996-2001. Psychiatry and Clinical Neurosciences 58, 611-618.

Faris R, Dunham H (1939). Mental Disorders in Urban Areas. University of Chicago Press: Chicago.

Fearon P, Morgan C (2006). Environmental factors in schizophrenia: the role of migrant studies. Schizophrenia Buletinl 32, 405-408.

Fearon P, Kirkbride JB, Morgan C, Dazzan P, Morgan K, Lloyd T, Hutchinson G, Tarrant J, Lun Alan Fung W, Holloway J, Mallett R, Harrison G, Leff J, Jones PBmMurray RM (2006). Incidence of schizophrenia and other psychoses in ethnic minority groups: results from the MRC AESOP Study. Psychological Medicine 36, 1541-1550.

Hanoeman M, Selten JP, Kahn RS (2002). Incidence of schizophrenia in Surinam. Schizophrenia Research 54, 219-221.

Hickling FW, Rodgers-Johnson P (1995). The incidence of first contact schizophrenia in Jamaica. British Journal of Psychiatry 167, 193-196.

Hollingshead A, Redlich RC (1958). Social Class and Mental Illness. Wiley: London.

Jablensky A, Sartorius N, Ernberg G, Anker M, Korten A, Cooper JE, Day R, Bertelsen A (1992). Schizophrenia: manifestations, incidence and course in different cultures: a World Health Organization ten-country study. Psychological Medicine 20, 1-97.
Kirkbride JB, Fearon P, Morgan C, Dazzan P, Morgan K, Tarrant J, Lloyd T, Holloway J, Hutchinson G, Leff JP, Mallett RM, Harrison GL, Murray RM, Jones PB (2006). Heterogeneity in incidence rates of schizophrenia and other psychotic syndromes: findings from the 3-center AESOP study. Archives of General Psychiatry 63, 250-258.

Kodesh A, Goldshtein I, Gelkopf M, Goren I, Chodick G, Shalev V (2012). Epidemiology and comorbidity of severe mental illnesses in the community: findings from a computerized mental health registry in a large Israeli health organization. Social Psychiatry and Psychiatric Epidemiology 47, 1775-1782.

Lynge I, Jacobsen J (1995). Schizophrenia in Greenland: a follow-up study. Acta Psychiatrica Scandinavica 91, 414-422.

Mahy GE, Mallett R, Leff J, Bhugra D (1999). First-contact incidence rate of schizophrenia on Barbados. British Journal of Psychiatry 175, 28-33.

Mallett R (1997). MRC Sociodemographic Schedule. Institute of Psychiatry: London.

McGrath J, Saha S, Welham J, El Saadi O, MacCauley C, Chant D (2004). A systematic review of the incidence of schizophrenia: the distribution of rates and the influence of sex, urbanicity, migrant status and methodology. BMC Medicine 2, 13.

Menezes PR, Scazufca M, Busatto GF, Coutinho LM, McGUIRE PK, Murray RM (2007). Incidence of firstcontact psychosis in Sao Paulo, Brazil. British Journal of Psychiatry 191, s102-s106.

Morgan C, Abdul-A1 R, Lappin JM, Jones P, Fearon P, Leese M, Croudace T, Morgan K, Dazzan P, Craig T, Leff J, Murray R (2006). Clinical and social determinants of duration of untreated psychosis in the AESOP first-episode psychosis study. British Journal of Psychiatry 189, 446-452.

Morgan C, Hibben M, Esan O, John S, Patel V, Weiss HA, Murray RM, Hutchinson G, Gureje O, Thara R, Cohen A (2015). Searching for psychosis: INTREPID (1): systems for detecting untreated and first-episode cases of psychosis in diverse settings. Social Psychiatry and Psychiatric Epidemiology 50, 879-893.

Morgan C, Lappin J, Heslin M, Donoghue K, Lomas B, Reininghaus U, Onyejiaka A, Croudace T, Jones PB, Murray RM, Fearon P, Doody GA, Dazzan P (2014a). Reappraising the long-term course and outcome of psychotic disorders: the AESOP-10 study. Psychological Medicine 44, 2713-2726.

Morgan C, McKenzie K, Fearon P (2008). Society and Psychosis. Cambridge University Press: Cambridge.

Morgan C, Reininghaus U, Fearon P, Hutchinson G, Morgan K, Dazzan P, Boydell J, Kirkbride JB, Doody GA, Jones PB, Murray RM, Craig T (2014b). Modelling the interplay between childhood and adult adversity in pathways to psychosis: initial evidence from the AESOP study. Psychological Medicine 44, 407-419.

Morgan C, Reininghaus U, Reichenberg A, Frissa S, the SELCoH study team, Hotopf M, Hatch SL (2014c). Adversity, cannabis use and psychotic experiences: evidence of cumulative and synergistic effects. British Journal of Psychiatry 204, 346-353. 
Rajkumar S, Padmavathi R, Thara R, Menon S (1993). Incidence of schizophrenia in an urban community in Madras. Indian Journal of Psychiatry 35, 18.

Selten J-P, Zeyl C, Dwarkasing R, Lumsden V, Kahn RS, Van Harten PN (2005). First-contact incidence of schizophrenia in Surinam. British Journal of Psychiatry 186, 74-75.

Tsoi W, Chen A (1979). New admissions to Woodbridge Hospital 1975 with special reference to schizophrenia. Annals of the Academy of Medicine, Singapore 8, 275-279.

Van Os J, Kenis G, Rutten BP (2010). The environment and schizophrenia. Nature 468, 203-212.

Varese F, Smeets F, Drukker M, Lieverse R, Lataster T, Viechtbauer W, Read J, van Os J, Bentall RP (2012). Childhood adversities increase the risk of psychosis: a meta-analysis of patient-control, prospective- and cross-sectional cohort studies. Schizophrenia Bulletin 38, 661-671.
WHO (1992). Schedules for Clinical Assessment in Neuropsychiatry. World Health Organization: Geneva.

WHO (1993). Personal and Psychiatric History Schedule. World Health Organization: Geneva.

Wig N, Varma VK, Mattoo S, Behere P, Phookan H, Misra A, Murthy RS, Tripathi B, Menon D, Khandelawal S

(1993). An incidence study of schizophrenia in India. Indian Journal of Psychiatry 35, 11.

Yucun S, Weixi Z, Liang S, Xiaoling Y, Yuhua C, Dongfeng Z, Hengyao S, Entao S (1987). A survey of mental disorders in a suburb of Beijing. International Journal of Mental Health 16, 75-80.

Zammit S, Lewis G, Rasbash J, Dalman C, Gustafsson JE, Allebeck P (2010). Individuals, schools, and neighborhood: a multilevel longitudinal study of variation in incidence of psychotic disorders. Archives of General Psychiatry 67, 914-922. 